\title{
The effects of plastic deformation on stress wave propagation in multi-layer materials
}

\author{
A. Tasdemirci ${ }^{\text {a }}$ I.W. Hall ${ }^{\text {b,* }}$ \\ ${ }^{a}$ Department of Mechanical Engineering, Izmir Institute of Technology, Gulbahce 35437, Izmir, Turkey \\ ${ }^{\mathrm{b}}$ Department of Mechanical Engineering, University of Delaware, Newark, DE 19716, USA
}

Received 13 February 2006; received in revised form 21 September 2006; accepted 3 October 2006

Available online 4 December 2006

\begin{abstract}
The behavior of a multi-layer material at high strain rate and the effect of plastic deformation on stress wave propagation were investigated by a combination of experimental and numerical techniques. Plastic deformation effects were studied in multi-layer materials consisting of ceramic, copper and aluminum subjected to large strains under high strain rate loading. First, stress wave propagation behavior for the monolithic metals was studied, and then extended to multilayer combinations of these metals with each other and with a ceramic layer. The axial stress distributions were found to be non-uniform in the elastic deformation range of the specimen. The degree of non-uniformity was much more pronounced in the multi-layer samples consisting of different materials. The presence of a ceramic layer increased the magnitudes of stress gradients at the interfaces. It was also found that a major effect of plastic deformation is a tendency to produce a more homogeneous stress distribution within the components. The implications of these observations for practical systems are discussed.
\end{abstract}

(C) 2006 Elsevier Ltd. All rights reserved.

Keywords: Multilayer structures; Numerical simulation; Plastic deformation; High strain rate; Stress wave propagation

\section{Introduction}

Thick-section, multi-layer composite materials are being increasingly used for many structural applications where penetration or perforation by foreign object impact is a possibility. As pointed out by Wilkins [1], the important parameters for resistance to penetration are stiffness (bulk and shear moduli), strength, density, and fracture resistance. These properties, along with a growing demand for low density, make it likely that few monolithic materials will be able to meet all the conflicting requirements. Consequently, new developments require innovative materials or structures in the broad category of composite materials and most of the practical composite structures designed to resist penetration are layered. The layers are usually combinations of fiber reinforced polymer composites, ceramics, and metals. Early composite targets were made by simply bonding a ceramic tile to a metal backing plate, the underlying idea being to use the hard ceramic layer to

\footnotetext{
*Corresponding author. Tel.: + 3028312421 ; fax: 3028313619

E-mail address: hall@me.udel.edu (I.W. Hall).
} 
defeat and erode the projectile, and to use the backing plate to absorb the impact energy and increase the fracture resistance of the target. Studies on ceramic armor composites are continuing to examine issues related to material failure, confinement, friction, and optimization of layering configuration [2-7]. Work by Potti and Sun [8] is an example involving polymer composites. Other research work on the impact response of layered composites can be found in Refs. [9,10].

A limited number of simplified analytical models have been derived and used for the analysis and optimization of materials consisting of layers of different materials, e.g., ductile multi-layered shields [11-13], aluminum/Lexan combinations [14], ceramic-faced armors [15-19]. However, besides material development, evaluating the impact response of composite targets is also a complex issue. Numerical simulations have been used extensively to study the impact response of composite structures [20-24] but there is as yet no consistent method available to evaluate and compare composites with different layering configurations and varying layer properties. In the absence of this, it is difficult to use case-by-case simulations to gain a systematic understanding of the ballistic response of composite structures. Without such a systematic understanding, development and optimization of composite structures often becomes a trial-and-error process.

Research also indicates that the full potential of ceramic hard facing layers has not been achieved because the interface between ceramic and metal has an unfavorable impedance mismatch that may even induce tensile failure. The emergence of functionally graded materials (FGM) provides a possible avenue for solving this problem since an FGM layer between the ceramic and metal can make the impedance change continuous rather than abrupt. FGM materials could, therefore, reduce the intensity of reflected stress waves, so the tensile stresses might be reduced or even removed entirely [25-28]. Gooch et al. [29] showed that functionally graded ceramic/metal structures presented potentially useful engineering advantages over conventional layered materials. Furthermore, Riou [30-32] performed experiments on bi-layered (ceramic/metal) configurations with different thicknesses of the ceramic layer. A significant degradation of the ceramic was observed in a normal impact test and fragmentation was caused by tensile hoop stresses and strains induced by the radial motion of the ceramic after impact. The multi-hit strength was low with these material combinations. However, when a porous ceramic preform was infiltrated by aluminum [33], the multi-hit capability was improved because motion of the fragments was avoided or reduced and the aluminum gave better cohesion to the impacted material, thereby increasing the residual strength after impact. Wave reflection and transmission phenomena at the interface of two dissimilar elastic solids are well known and are, then, critically important at ceramic/metal interfaces. In this paper, the propagation characteristics of impact waves across a planar interface between ceramic/metal and metal/metal layers are reported and plasticity effects are shown for the first time to be particularly important in these multilayer materials comprising metal layers.

From the point of view of modeling material behaviors, plastic deformation is a strong link between the totally elastic solution and those solutions including damage effects. Although mechanical testing of conventional metallic materials at high strain rates is a relatively mature technical undertaking [34-37], the high strain rate behavior of multilayer materials including these metallic materials is still not fully understood. Powerful numerical tools can help to understand the behavior so the present research had two major goals. The first was to investigate for the first time stress wave propagation in multilayer materials containing metal layers by means of an experimentally validated numerical model. The second goal was to demonstrate and understand the effect of plastic deformation on stress wave propagation. The multilayer materials investigated consisted of ceramic, copper and aluminum and we begin by briefly studying stress wave propagation behavior for the monolithic metals, and then extending it to multilayer combinations of these metals with each other and with a ceramic layer. The ultimate goal is to extend this approach to more complex multi-layer materials.

\section{Experimental and modeling}

Samples were prepared from multi-layer plates with layers of widely different acoustic impedances. The samples consisted of two layers, namely a $13.96 \mathrm{~mm}$ thick alumina ceramic front layer and a $13.4 \mathrm{~mm}$ thick layer of 6061-T6 aluminum alloy or electronic-grade copper (alloy 110). The acoustic impedance values of ceramic, aluminum and copper alloy are $32.0 \times 10^{5}, 17.0 \times 10^{5}$ and $41.6 \times 10^{5} \mathrm{gm} / \mathrm{cm}^{2} \mathrm{~s}$, respectively, so the combinations investigated cover a significant range of impedance mismatches. Cylindrical samples, $15.94 \mathrm{~mm}$ in diameter, were core-drilled from the plates in the through-thickness direction. Samples were fitted with 
strain gages to monitor real-time strains/stresses during the course of the tests. Strain gages with $0.79 \mathrm{~mm}$ element lengths were used generally, although several tests were also carried out with an array of gages designed to measure the strain simultaneously at several locations along the sample length and thus provide a strain/time/position map of the wave passage. When present, the ceramic layer was always at the impacted side.

Samples were compression tested over a range of displacement rates using the SHPB apparatus with striker bar velocities of 10 and $16 \mathrm{~m} / \mathrm{s}$. As an approximate guide, these velocities would generate "average strain rates" of $\sim 400$ and 600 per second, respectively, in homogeneous, single component, copper or aluminum samples. The particular SHPB apparatus used consists of Inconel 718 bars, a $356 \mathrm{~mm}$ long striker bar, $3450 \mathrm{~mm}$ incident bar, and $1850 \mathrm{~mm}$ transmitter bar, all with a diameter of $19.05 \mathrm{~mm}$. Further details of the experimental set-up have been reported elsewhere [38].

It should be noted that the SHPB apparatus was used in a novel manner in this work. It cannot be used to generate mechanical property data in the conventional way since essentially all of the necessary assumptions are violated. Also, it is well known that the loading condition of SHPB experiments is axisymmetric at best, and the bar-specimen interactions and interactions between different layers of materials are not planar. Therefore, for materials composed of several layers of distinctly different materials, the response of each individual layer is a function of its thickness and material properties as well as those of adjacent layers. Nevertheless, SHPB tests may be performed on multilayer specimens and data generated and recorded from strain gages on the bars in the conventional manner. Although these data cannot be reduced by the usual routines, numerical simulation procedures (models) have been developed which reproduce the output data of these SHPB experiments; the SHPB is essentially being used to validate the models. When experimental and calculated values closely match, (a) confidence in the simulations is achieved and, (b) the tests themselves can actually be interpreted. The SHPB is thus used basically as a "probe" to generate a measurable response and when the same response is reproduced by the model, the processes and phenomena incorporated into the model must closely correspond to those occurring within the "black-box" of the test.

An additional complication present in conventional SHPB testing, is that differences in the initial crosssectional areas of the bars and specimen layers, and in their transverse expansions under axial compression, can lead to elastic or inelastic indentation into the bar(s) and/or specimen layer(s) in contact. This can cause radial constraints and consequently stress concentrations in vicinity of the interfaces, regardless of whether they are frictional or frictionless. However, these effects are easily incorporated into the numerical models used and their presence does not prevent useful interpretations of results. Nevertheless, early tests were performed with impedance matched tungsten carbide platens between the specimen and bars to minimize the indentation and any such specimen end effects: later experiments confirmed that, although they were unnecessary for purposes of accuracy because of the relatively low striker bar velocities used here, they were still useful to protect the bar surfaces.

A three-dimensional SHPB finite element model was used to study stress wave propagation in the multilayer materials and also in the individual components. The analyses were performed using the commercial explicit finite element code LS-DYNA 970. Two axes of symmetry were assumed so only one quarter of the bar was modeled. For each test modeled, the output was displayed at several locations within the sample as well as at the location of the strain gages on the incident and transmitter bars of the SHPB apparatus: these locations are indicated by letters in the insets in the figures below. The desired ideal result, then, is that data calculated from the model closely match output from the strain gages on the incident and transmitter bars. Similarly, output measured by gages on the sample should also closely match data calculated from the model. If all these conditions are met, it indicates that the model is accurately capturing the wave propagation behavior inside the sample and bars. The model can then be used with confidence to determine local conditions at any point within the sample: this information can be used, for example, to predict fracture initiation sites, local stress gradients. It should be borne in mind that only elastic and elastic-plastic waves were encountered in the present study.

The model has three components in contact: the incident and transmission bars each of length $1524 \mathrm{~mm}$, and the specimen, i.e., the ceramic, copper and aluminum layers (the thicknesses of which are 13.96, 13.40 and $13.40 \mathrm{~mm}$, respectively). The bar diameter is $19.05 \mathrm{~mm}$ and the diameter of the specimen is $15.94 \mathrm{~mm}$. The component materials are modeled with eight nodes solid elements and the bar-specimen interfaces are modeled 
with the automatic contact sliding interfaces without friction, all other interfaces are considered perfectly bonded. A total of 75 elements are used in the model for the cross-section, which provides 10 elements across the radius of the bars. 400 elements are used along the length of the bar. Mesh biasing along the bar axis is utilized to refine the meshes at the contact interfaces. The impact velocity of the striker bar $(V=10$ and $16 \mathrm{~m} / \mathrm{s}$ ) has been defined as the initial condition and all other boundaries are traction free and can move in any direction. A rectangular stress pulse is also taken as the input to the impact face of the incident bar for the elastic case solutions. In order to reduce computation time, the simulation uses bars $1524 \mathrm{~mm}$ in length instead of full-length bars. It will be seen later from the figures that this has the effect of decreasing the transit time between successive waves and shortening the wave duration slightly: however, it does not affect the basic wave-shapes or amplitudes. Trial computations were carried out using full-length bars, but apart from the slightly smaller time window, no significant differences were found and the shorter bars were used in all calculations henceforth.

Material properties used in the finite element code are shown in Table 1. The ceramic was modeled with an isotropic elastic material model and the Inconel bars were modeled with an isotropic elastic material model. Aluminum and copper alloys were modeled with a piecewise linear plasticity material model which is an elasto-plastic material model with an arbitrary stress-strain curve and in which an arbitrary strain rate dependency can be defined. Experimentally generated stress vs. strain curves are used as input to LS-DYNA.

\section{Results}

The experimental results are presented here in order of increasing incident bar velocity corresponding to increasing loading rate and, as will become clear, increasing degrees of plastic deformation within the copper and aluminum layers. Comparison of quasi-static and dynamic data for the individual materials indicated that much of the ceramic deformation could be modeled as elastic deformation.

\subsection{Tests on individual component materials}

SHPB tests and simulations were first performed for the single material cases, i.e., ceramic only, aluminum only and copper only. Figs. 1(a) and (b) show a comparison of the experimental and numerical simulation results for the aluminum sample and represent data from strain gages mounted on the incident and transmitter bars. Clearly there is good consistency between the model and experiment. The principal difference between experimental and calculated data is a slightly lower resolution for the experimental data since the actual strain gages on the bars have a length of $3.2 \mathrm{~mm}$ and tend to average out, or 'smear', the data acquisition process whereas the calculation reports data from a specific element $1.6 \mathrm{~mm}$ in length on the bar surface. This observation should also be kept in mind for subsequent comparisons between experimental and calculated data from the samples themselves. This initial testing established the yield stresses of the copper and aluminum as $\sim 220$ and $280 \mathrm{Mpa}$, respectively. The strain hardening exponents, considered further below, were calculated to be 0.07 and 0.14 , respectively.

Fig. 2(a) shows the longitudinal stress (z-stress) in an aluminum sample, calculated at three elements, one close to each interface and one at the specimen's mid-section as indicated in the inset. It can be clearly seen that the material experiences a uniform stress distribution throughout the entire duration of the test. Similar behavior was recorded for the copper samples.

Table 1

Material properties used in finite element models

\begin{tabular}{lllll}
\hline Material & Modulus of elasticity $(\mathrm{GPa})$ & Poisson ratio & Density $\left(\mathrm{kg} / \mathrm{m}^{3}\right)$ & Yield stress $(\mathrm{MPa})$ \\
\hline Copper & 127.0 & 0.35 & 8930 & 280 \\
Aluminum & 68.9 & 0.33 & 2700 & 220 \\
Inconel & 207.0 & 0.30 & 7850 & - \\
\hline
\end{tabular}



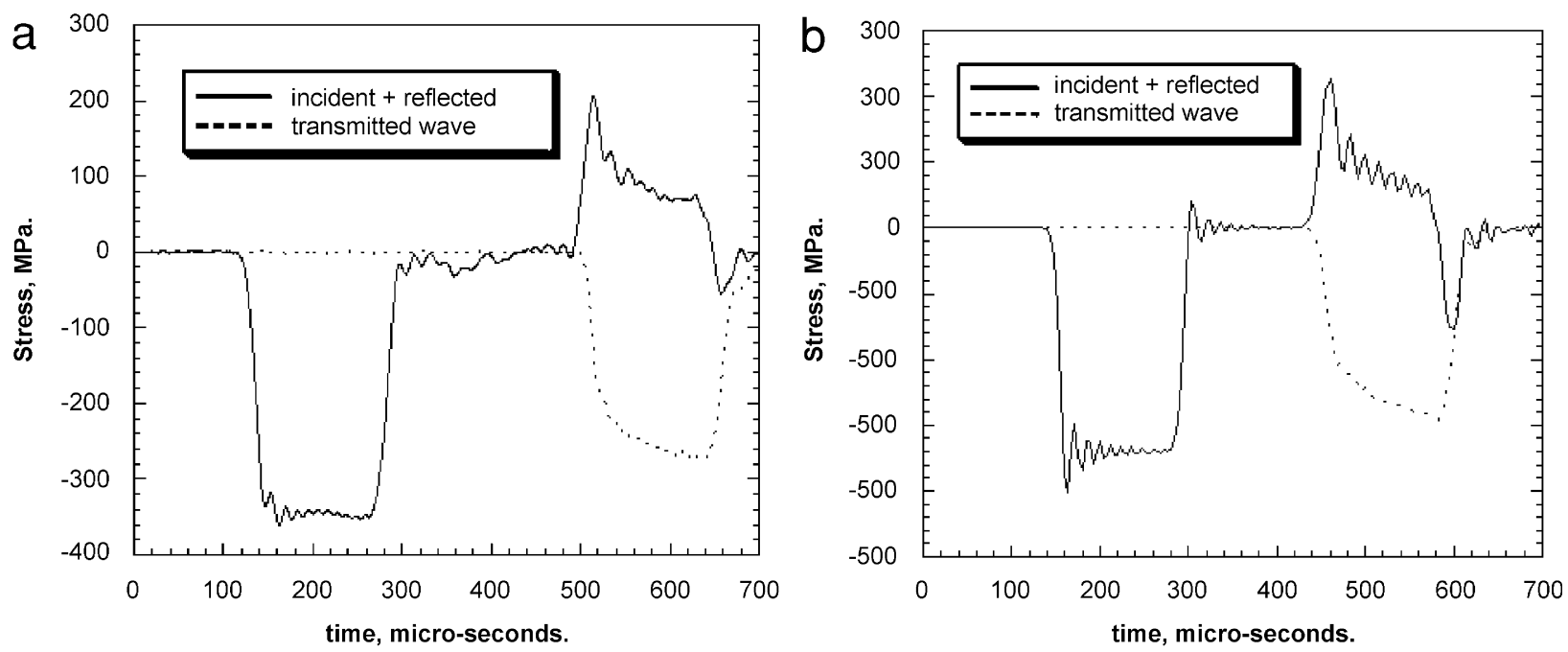

Fig. 1. (a) Experimental and (b) calculated output from strain gages on the incident and transmitter bars during a test on an aluminum sample.
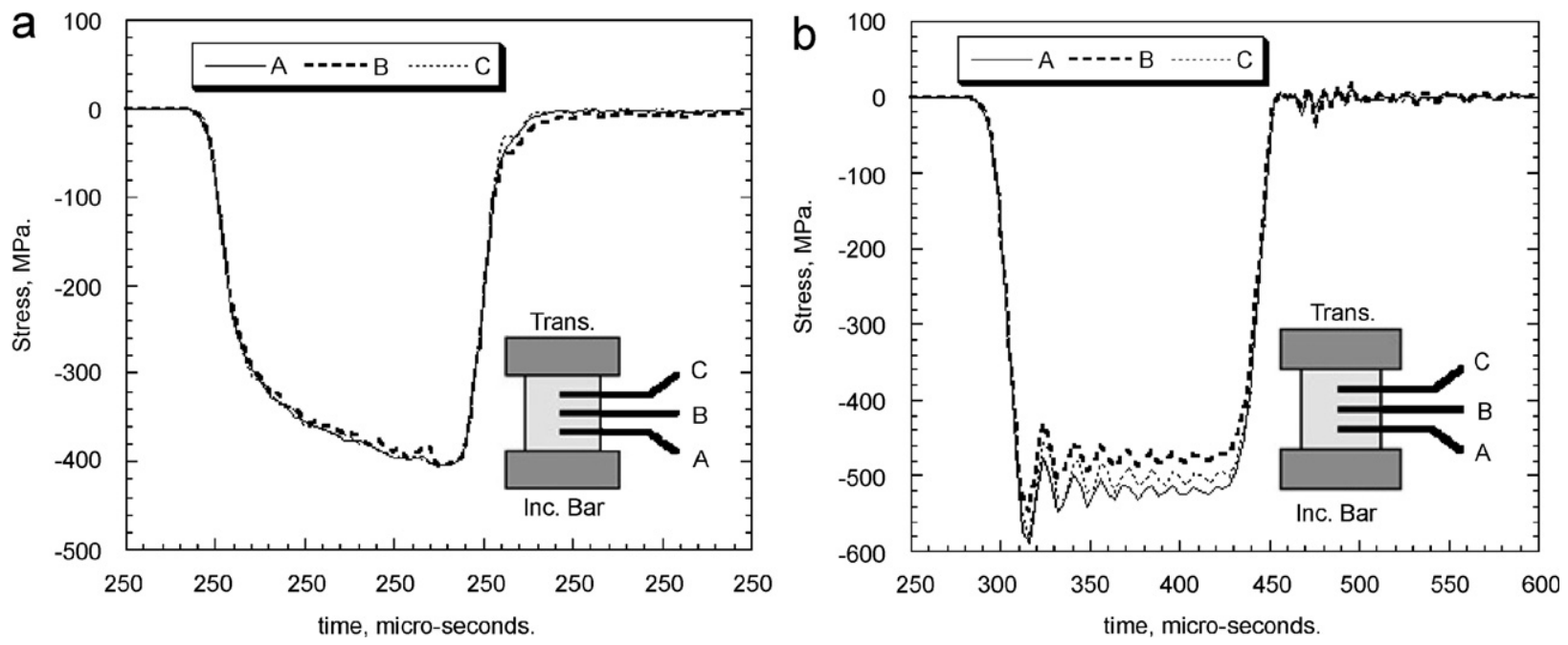

Fig. 2. (a) Z-stress calculated at three elements on an aluminum sample and (b) on a ceramic sample.

Tests on the ceramics, however, showed that the $z$-stress distribution was not uniform throughout the sample, Fig. 2(b), and was significantly higher at the incident bar/sample interface than at the sample midlength. These observations were independent of strain rate within the range investigated and show that the homogeneous state of stress usually assumed to exist in such specimens after 3 or 4 wave reverberations is not, in fact, achieved.

\subsection{Tests on two-layer samples at $10 \mathrm{~m} / \mathrm{s}$}

\subsubsection{Ceramic/metal}

Next, tests were performed on double layer, ceramic/aluminum and ceramic/copper, samples and Figs. 3(a) and (b) show examples of experimental and calculated data from the ceramic/aluminum specimen tested at a striker bar velocity of $10 \mathrm{~m} / \mathrm{s}$. Again, the data match closely, showing that numerical simulation 

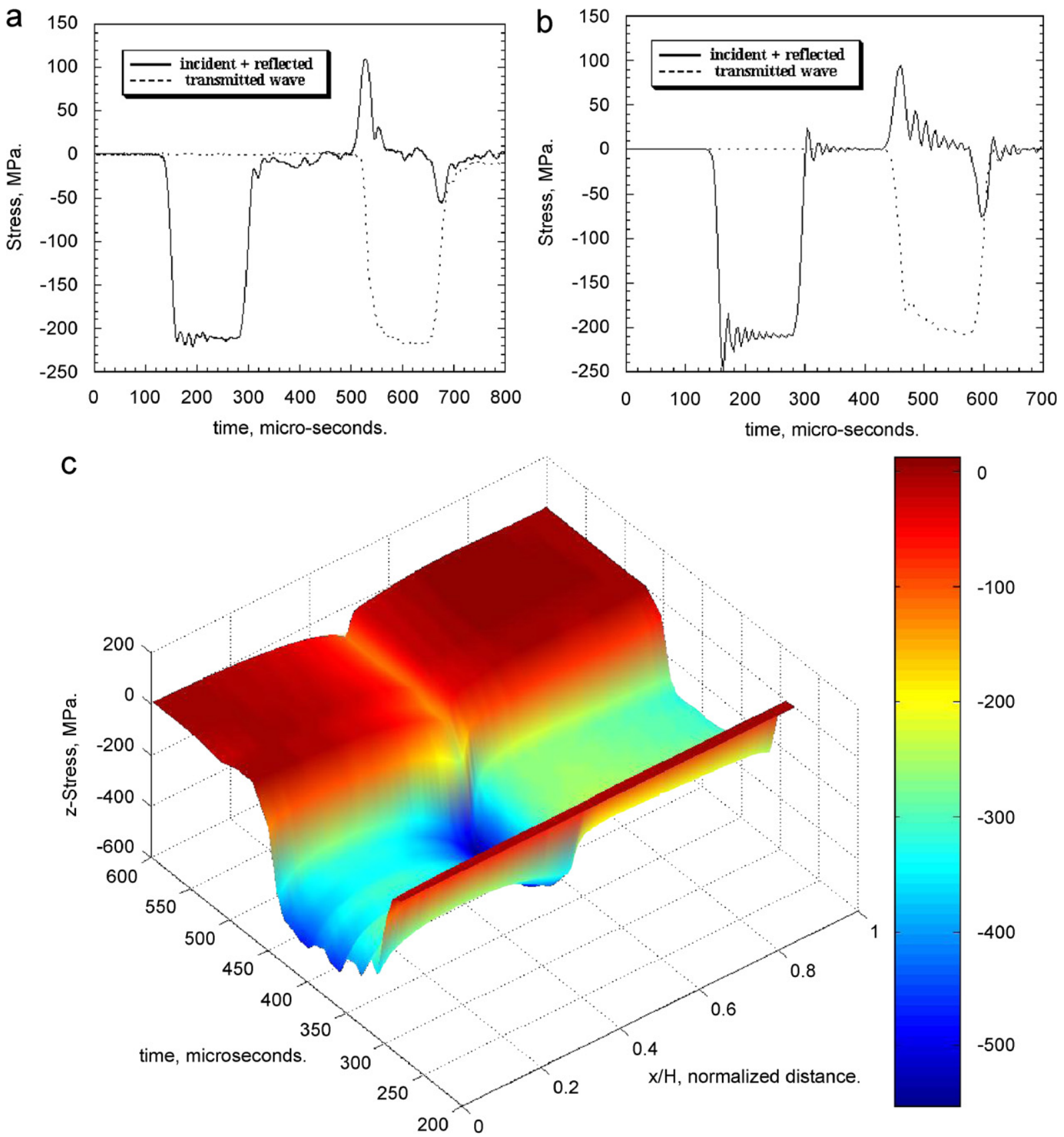

0

$-100$

$-200$

$-300$

$-400$

$-500$

Fig. 3. (a) Experimental and (b) calculated output from strain gages on the incident and transmitter bars during a test on a ceramic/ aluminum specimen and (c) stress-distance-time maps showing response of ceramic/aluminum specimen.

accurately captures the details of wave propagation. Fig. 3(c) shows the calculated stress/distance/time plot of this sample: the normalized distance $x / H=0$ corresponds to the incident bar/ceramic interface and $x / H=1$ corresponds to the aluminum/transmitter bar interface. Fig. 3(c) shows that, during the course of testing, the ceramic experiences a non-uniform stress distribution, with the minimum occurring at the sample mid-length whereas aluminum experiences a more uniform stress distribution as compared to ceramic. This type of figure also clearly demonstrates the severe stress gradients present at the ceramic/metal interface. 
An important aspect of this work has been the extensive use of strain gages positioned on the sample surfaces to generate measured data for comparison with the numerical data. Since a significant amount of plastic strain occurs in the metal samples, strain data are generally left as such here and are not converted to stress data by assuming a constant value for Young's modulus. Figs. 4(a)-(d) show numerical and experimental data from the individual ceramic and aluminum portions respectively. The elements chosen for the numerical data were the same as for single layer tests in Fig. 2 above. It should be noted, however, that there is now a significantly greater amount of strain variation within the ceramic portion of the sample length (Fig. 4(a)) when compared with Fig. 2(b). The ceramic is now even further from a state of uniform strain (and, hence, stress, since it is still in the elastic range) than when tested alone.

Generally, the numerical data show broadly similar behavior to the experimental data in each component, including similar scales of stress inhomogeneity, similar magnitudes of the maximum stress, and a similar overall shape to each strain vs. time curve. On account of their relatively large size, the strain gages cannot, however, capture the rapid, localized stress oscillations that are seen, for example, in Fig. 4(a). This ability to resolve fine-scale details of the stress/time history, constitutes one of the major advantages of the present modeling approach. Note also the presence of residual plastic strain in the aluminum layer after unloading.
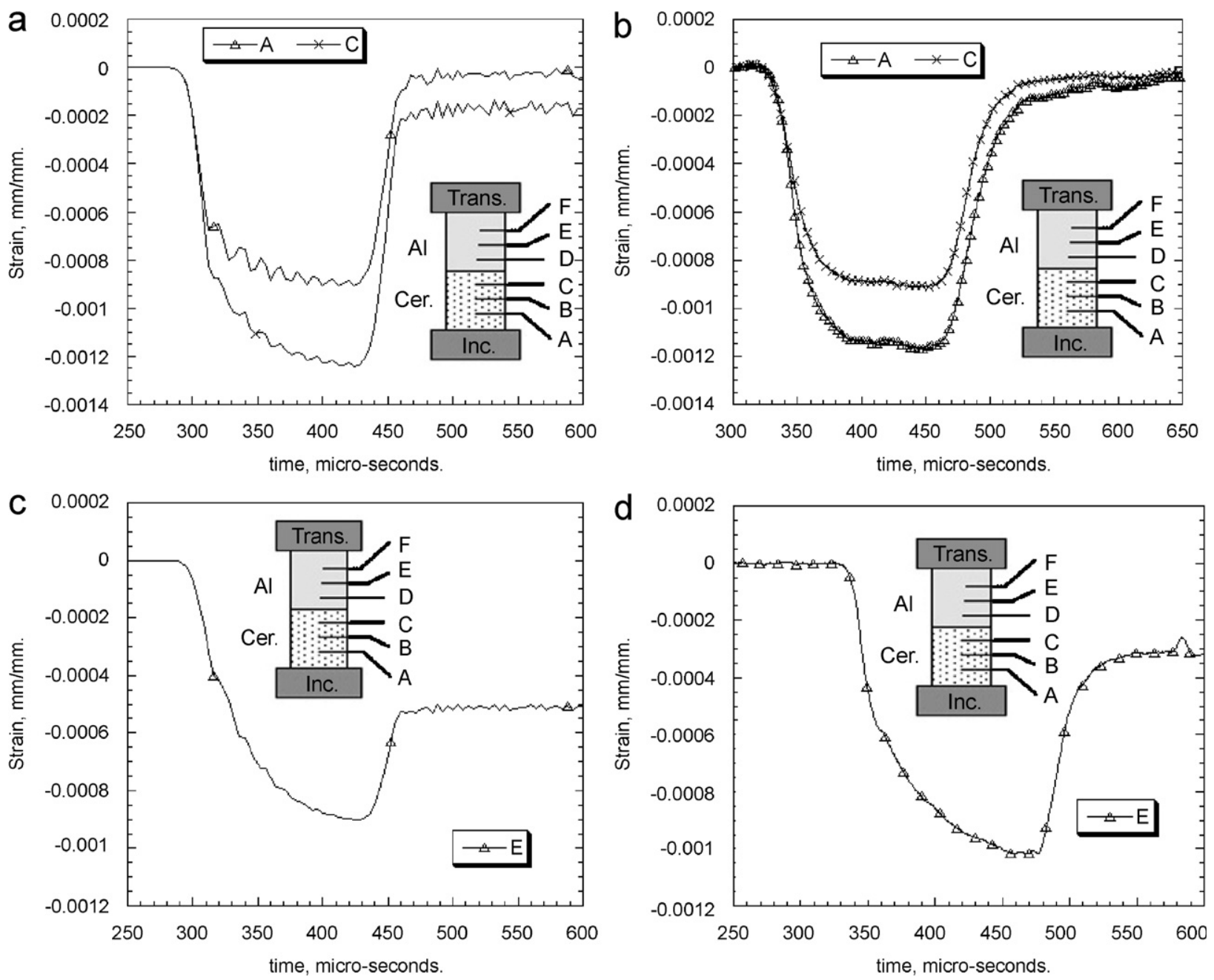

Fig. 4. (a)-(d) Data from ceramic/aluminum sample: (a) calculated strain distribution at 2 elements within the ceramic, (b) measured strain from strain gages on ceramic, (c) calculated strain distribution at aluminum mid-length, and (d) measured strain from strain gage on aluminum mid-length. 
Figs. 5(a)-(d) show similar numerical and experimental data from the individual ceramic and copper layers respectively.

Again, the experimental and numerical data show similar responses in each case, including residual plastic strain level in the copper layer. It is seen that the copper layer showed a residual plastic strain of only $\sim 0.2 \%$ as compared with $\sim 0.4 \%$ for the aluminum sample, despite the significantly lower yield stress of the former. Note also that the general shape of the ceramic data varies according to the nature of the metallic rear layer: with an aluminum layer the shape resembles that of the single layer aluminum data (Fig. 2(a)), rising rapidly at first and then more gently to a maximum stress just before unloading. When a copper backing plate is used, the ceramic data show the more flat-bottomed shape that was characteristic of the single layer ceramic sample, Fig. 2(b).

Fig. 6 shows the calculated axial stress distribution through the thickness for ceramic/aluminum and ceramic/copper specimens at two different time values, namely 340 and $400 \mu$ s after the start of the test. It is seen that, at any instant, there is a significantly greater amount of strain variation throughout the length of the ceramic portion of the ceramic/metal specimens than through the metal portion. Furthermore, in addition to the variation with length, the aluminum portion shows more variation with time than the copper specimen.
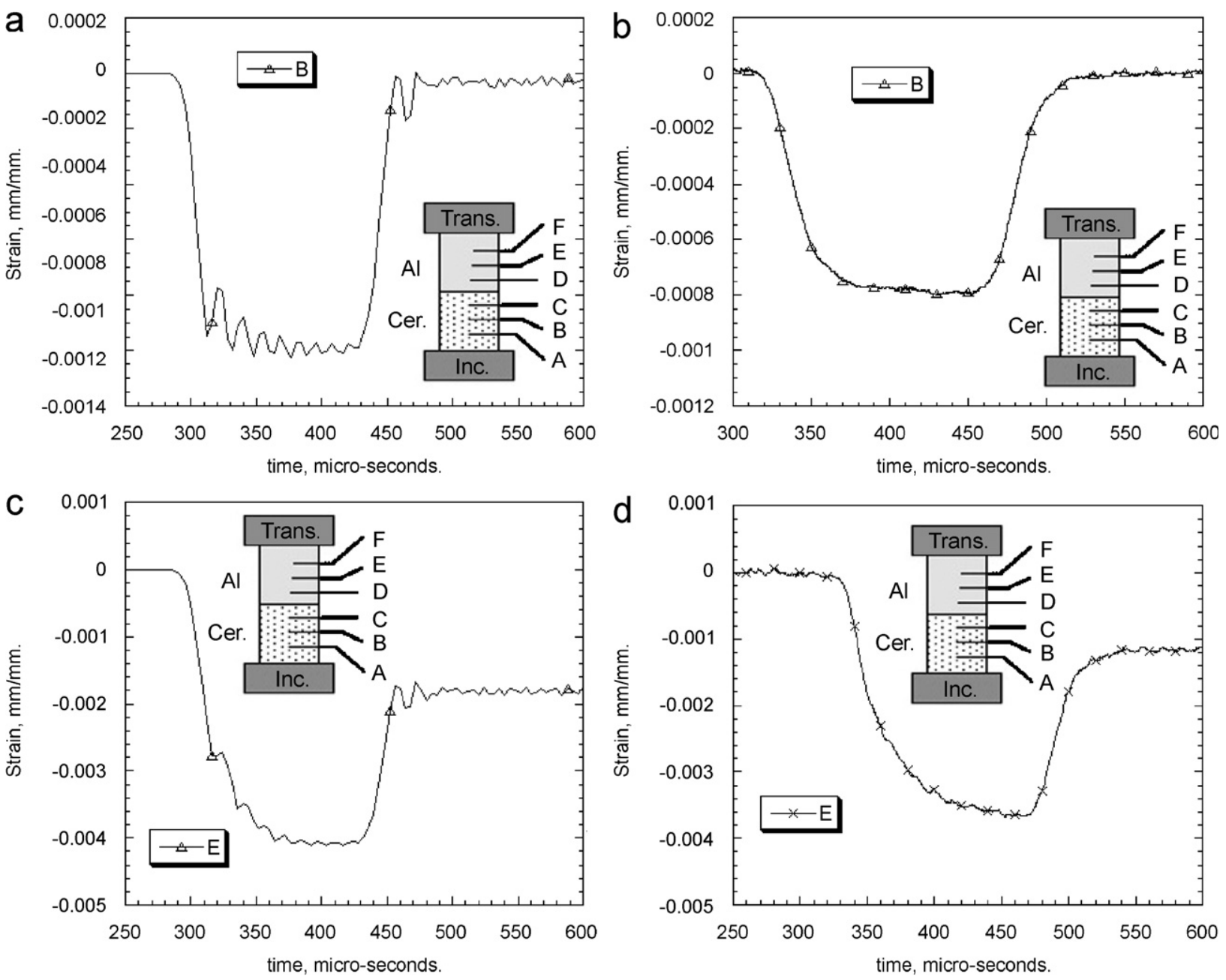

Fig. 5. Data from ceramic/copper sample: (a) calculated strain distribution at an element within the ceramic, (b) measured strain from strain gages on ceramic, (c) calculated strain distribution at copper mid-length, and (d) measured strain from strain gage on copper midlength. 


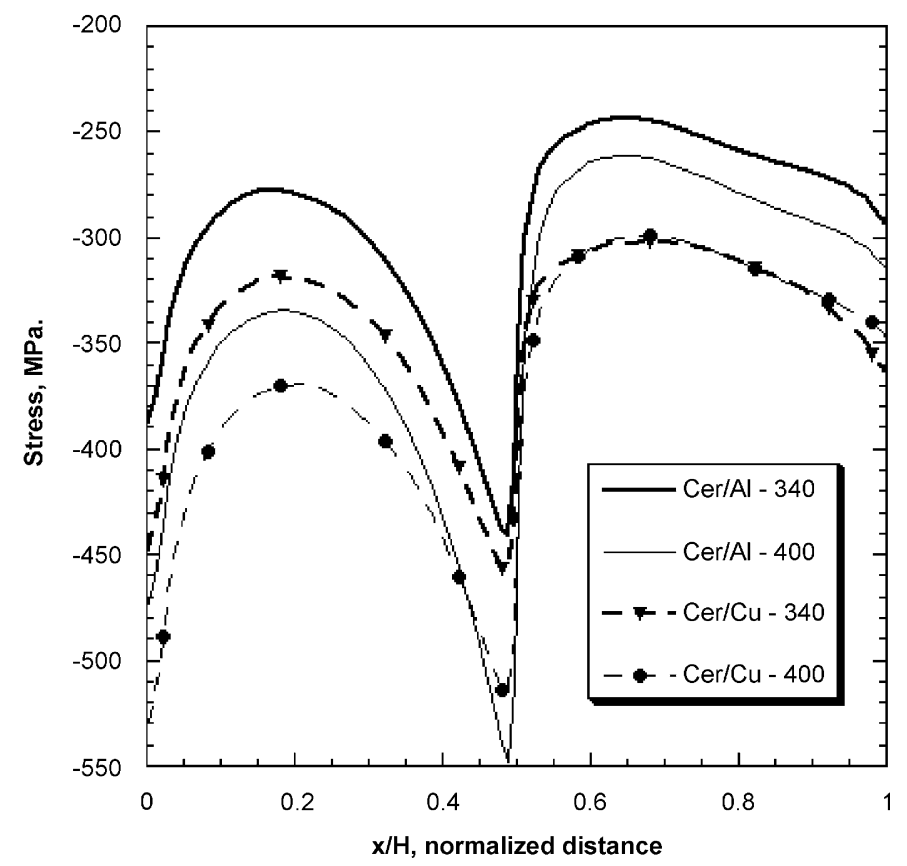

Fig. 6. The axial stress distribution through the thickness for ceramic/aluminum and ceramic/copper specimens at two different time values.

It should also be noted that the stress gradient across the interface is very severe, as the stress rises from $\sim 250 \mathrm{MPa}$ in the aluminum to $\sim 550 \mathrm{MPa}$ in the ceramic in the few microns across the interface.

In order to investigate the distribution of axial stress along the length of the specimen in the complete absence of any plastic deformation, an SHPB numerical simulation was performed for a two-layer ceramicaluminum specimen subjected to a rectangular stress pulse with maximum amplitude of $100 \mathrm{MPa}$. Fig. 7 shows the numerical Hopkinson bar response for this ceramic/aluminum specimen. In order to study the axial stressstate of the specimen, element time-histories of the specimen through the thickness were analyzed. Fig. 8 shows the axial stress distribution through the thickness for three different time values. These stress profiles represent purely elastic behavior of the specimen since the stress was not high enough to cause any plastic deformation. Stress concentrations are found at the ceramic/aluminum interface, as well as at the input and output interfaces, and the ceramic layer showed a minimum stress value at its mid-length, while the aluminum layer showed a minimum very close to the ceramic-aluminum interface. At the ceramic-aluminum interface $(x / H=0.5)$, the axial stress is about $57 \%$ more than that at $x / H=0.57$. During elastic deformation, the stress varied with position within the components but did not vary with time in either component. Similar results were found for the ceramic-copper and copper-aluminum specimens. Numerical simulation results revealed that stress uniformity was not achieved in the specimen during elastic deformation for any possible two-layer combinations.

\subsubsection{Metal/metal}

A similar set of experiments and simulations was then carried out for the copper/aluminum material configuration. Fig. 9 shows the calculated stress/distance/time plot for a copper/aluminum sample. The principal difference between this and the ceramic/aluminum case, Fig. 3, was that plastic deformation led to a more uniform stress distribution inside the sample than was found when a ceramic layer was present, despite an initial (elastic) acoustic impedance mismatch of 2.45 as compared to 1.88 . The stress gradient at the interface between layers was now considerably reduced. Tests were also performed with the layer order reversed, i.e., the wave entered the aluminum first and then the copper. Experimental records from these aluminum/copper tests were essentially identical with those from copper/aluminum tests. 


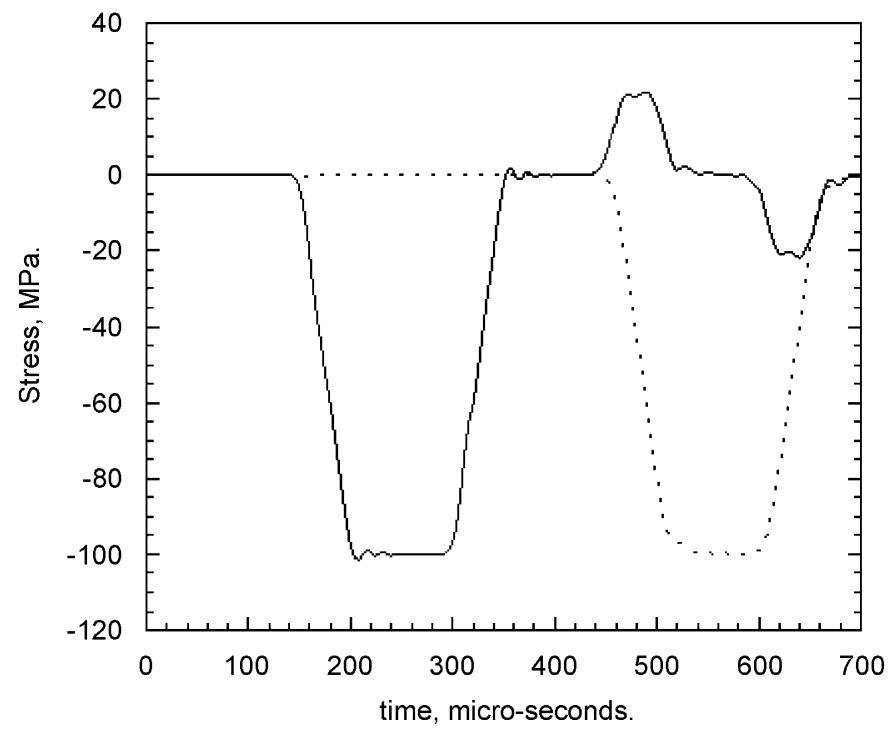

Fig. 7. Numerical Hopkinson bar response for a ceramic/aluminum specimen.

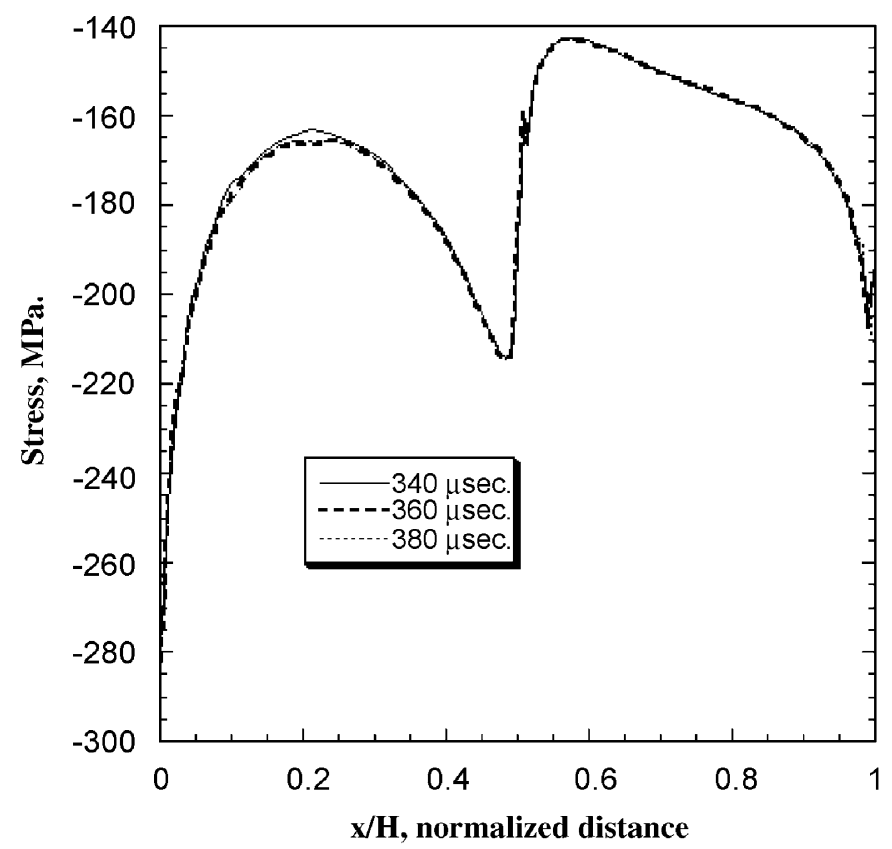

Fig. 8. Axial stress distribution through the thickness for three different time values during the test showing stress values are invariant.

\subsection{Tests on two-layer samples at $16 \mathrm{~m} / \mathrm{s}$}

\subsubsection{Ceramic/metal}

Experiments and simulations were repeated for a higher striker bar velocity. Figs. 10(a) and (b) show experimental and numerical SHPB data from a ceramic/aluminum sample, tested at a striker bar velocity of $16 \mathrm{~m} / \mathrm{s}$. Fig. $10(\mathrm{c})$ shows the calculated stress/distance/time plot for a ceramic/aluminum sample. The shapes of the transmitted and reflected waves for this higher impact velocity are now found to be drastically different from the lower velocity case. The increase of striker bar velocity contributes to a great 


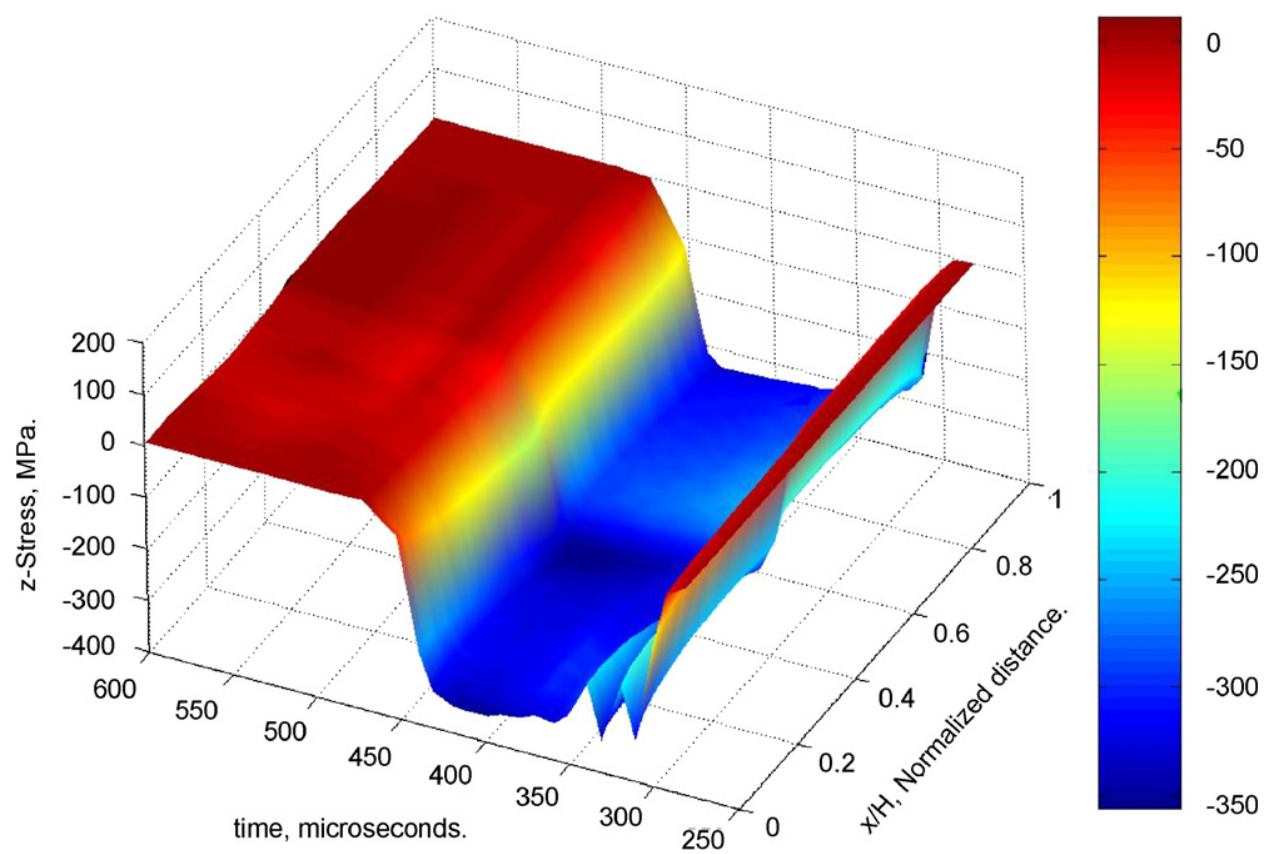

Fig. 9. Stress-distance-time map showing response of copper/aluminum specimen for a striker bar velocity of $10 \mathrm{~m} / \mathrm{s}$.

increase in residual stress/strain levels within the aluminum layer close to the ceramic/aluminum interface as evidenced by the deep 'groove' remaining even after the wave has passed completely at $t>500 \mu \mathrm{s}$ and unloading has begun. When compared with the lower striker bar velocities, somewhat more uniform stress distribution is observed within both layers. As the striker bar velocity increases, it is observed that the region of high stress concentration moves from the incident bar/ceramic interface to the ceramic/ aluminum interface.

Figs. 11(a)-(d) show experimental and numerical data from the individual ceramic and aluminum layers. Note that there is now more than $2 \%$ residual strain in the aluminum layer. The numerical data show very similar behavior to the experimental data in each case, including rapid stress rise in the ceramic, similar scales of stress/strain, similar magnitudes of the maximum and residual stress, and a similar overall shape to each stress vs. time curve. Corresponding data for the ceramic/copper specimens revealed almost identical behavior.

SHPB tests and simulations were also performed for the ceramic/copper case. It was found, both experimentally and numerically, that the reflected wave exhibits an initial peak of $\sim 120 \mathrm{MPa}$, as compared to $\sim 180 \mathrm{MPa}$ for the ceramic/aluminum case (Fig. 10(a)), that slowly decreases to $\sim 60 \mathrm{MPa}$. The difference in the amplitude of the reflected (and transmitted) waves arises from the different reflection and transmission coefficients and different plastic deformation behaviors. The issue of differing transmission coefficients will be discussed further below. Uniform stress distribution is observed in the copper layer during the later stages of the deformation. The occurrence of plastic deformation of the layer and a low work hardening exponent is the main cause of this behavior.

\subsection{2. $\mathrm{Metal} / \mathrm{metal}$}

Figs. 12(a) and (b) show experimental and calculated data from the incident and transmitter bars for the copper/aluminum case while Fig. 12(c) shows the calculated stress/distance/time plot for a copper/aluminum specimen. Two features are particularly notable for this configuration; first, both components experienced highly uniform stress distribution and, second, a region of considerable tensile residual stress is generated in the copper layer adjacent to the interface. Also, because of the higher initial striker bar velocity, a significant amount of residual plastic strain remains after the impact. 

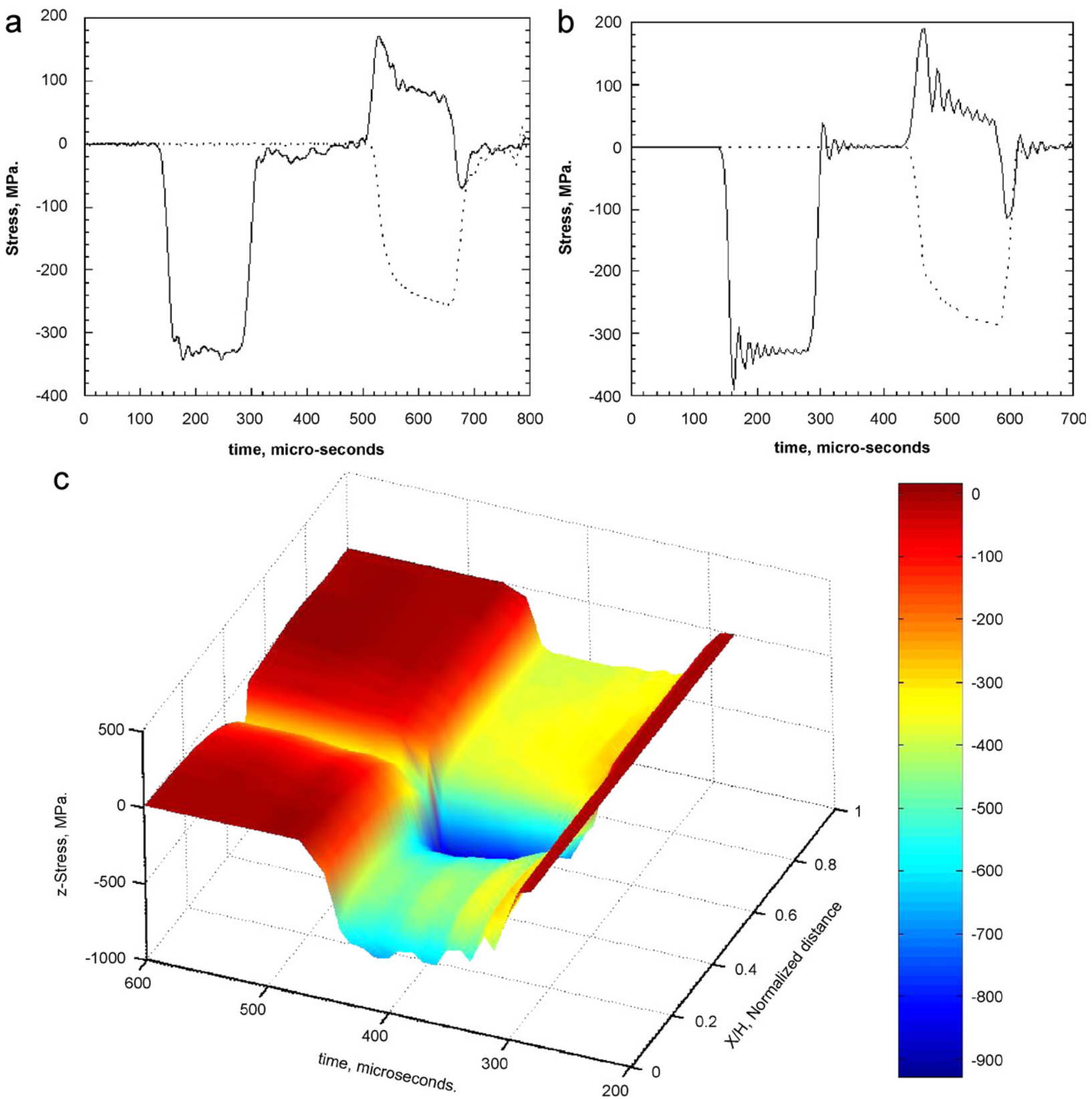

Fig. 10. (a) Experimental and (b) calculated output from strain gages on the incident and transmitter bars during a test on a ceramic/ aluminum specimen and (c) stress-distance-time maps showing response of ceramic/aluminum specimen for a striker bar velocity of $16 \mathrm{~m} / \mathrm{s}$.

\section{Discussion}

Ceramic materials have been found to be effective agents against impulsive impact, when suitably supported by a backing plate material. Applications include, among many others, turbine blade containment structures and ballistic armor. Ceramics typically have five to ten times the compressive strength of high-strength steel and only one-half its density. Unfortunately, since their tensile strength is low, their integration into containment schemes must be carefully considered otherwise fragmentation from elastic stress or shock waves, not penetration, is more likely to cause the system to fail. Initial impulsive impacts occur at a point and 

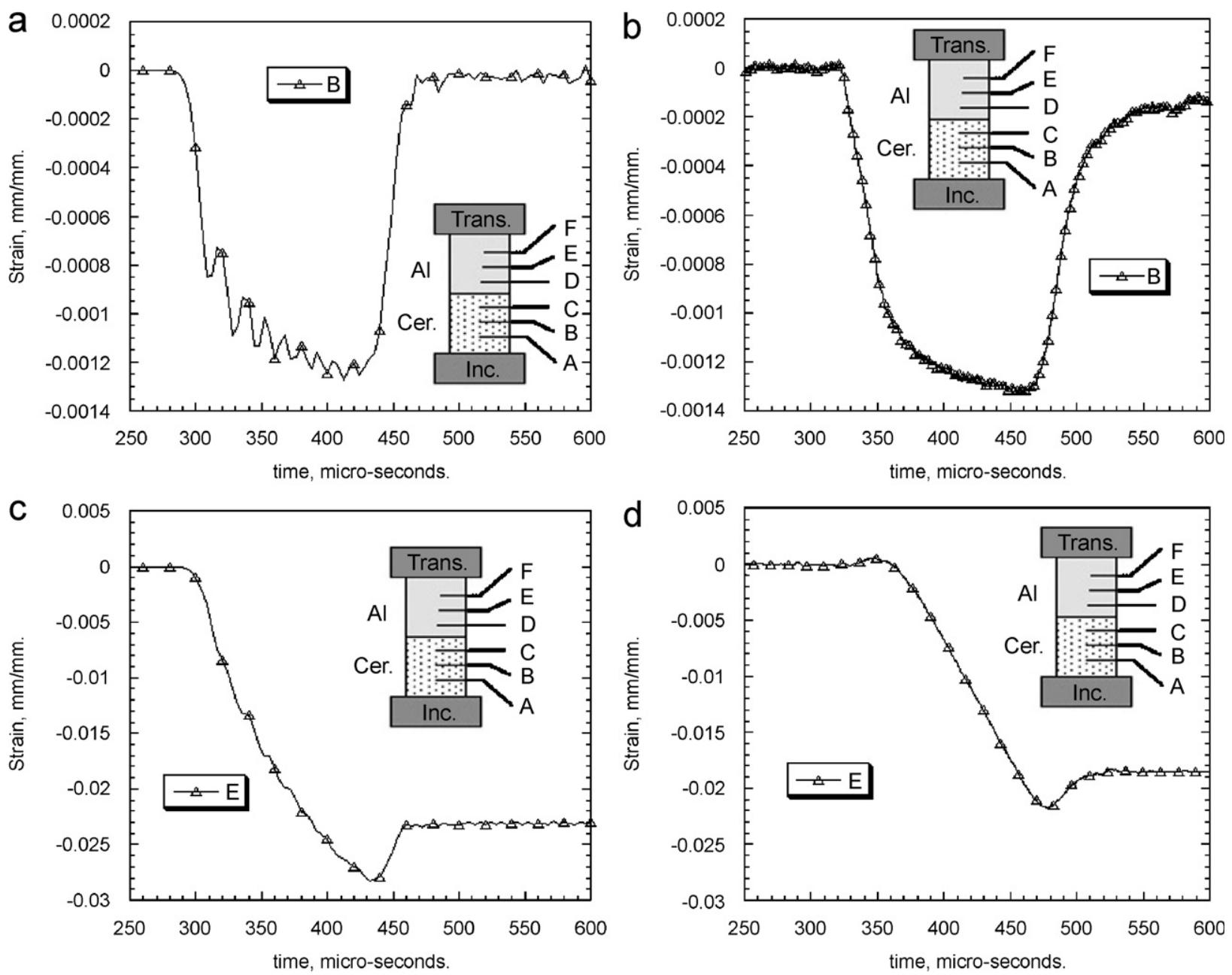

Fig. 11. Strain measured on ceramic: (a) calculated and (b) experimental. Strain measured on aluminum: (c) calculated and (d) experimental.

produce spherical waves below the ceramic layer. Without support material behind it, the ceramic is likely to suffer damage in two ways. At early times, i.e., times characteristic of wave transit across the thickness of the ceramic plate or tile, the free boundary condition will cause the generation of reflected normal and shear stress waves equal in magnitude, but opposite in phase, to the incident wave; these waves can cause the ceramic to fragment internally. At later times, i.e., times characteristic of wave transit across the width, the ceramic will bend and the momentum of the projectile will sustain the bending until structural failure occurs.

Consideration of how this picture may be affected by the presence of a metallic backing layer provided part of the motivation for the present study. These effects are also relevant for newly developed ceramic/metal functionally graded materials (FGM) as well for ceramic/metal or ceramic/composite armors. In FGM the properties vary continuously with no discrete interface boundaries. The presence of ceramic/metal and metal/ metal interfaces in ceramic/metal armor and FGM necessitates the investigation of the propagation characteristics across these interfaces in order to be able to successfully model their behavior under dynamic loading. Study of the propagation characteristics of impact waves across a planar interface between ceramic and adjacent metal layers is a necessary first step. The present work shows that plasticity effects are particularly important in these multilayer materials. Plastic deformation is a strong link between the relatively straightforward totally elastic solutions and the much more complex solutions which include damage effects in both the ceramic and metal. 

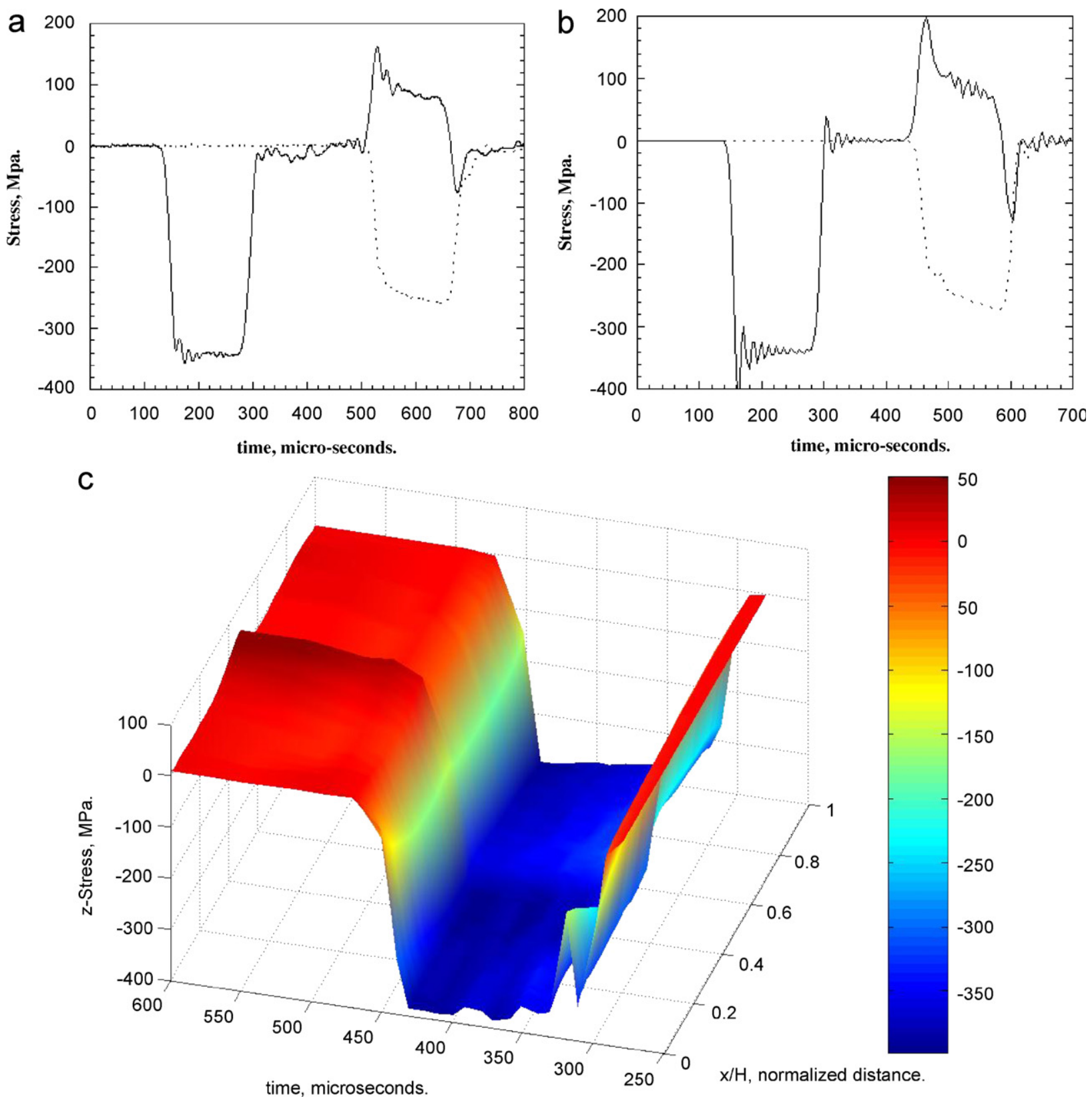

Fig. 12. (a) Experimental and (b) calculated output from strain gages on the incident and transmitter bars during a test on a copper/ aluminum specimen and (c) stress-distance-time maps showing response of copper/aluminum specimen.

One of the most important assumptions made in the classic one-dimensional Hopkinson bar theory, and one that is the key to deriving readily interpreted data from such tests, is that the specimen deforms under uniaxial stress once a homogeneous stress distribution (equilibrium) is achieved within the specimen after a few microseconds of 'ringing up' time. Figs. 2(b) clearly shows, however, that this assumption cannot be satisfied even for a single isotropic layer under some circumstances, while Figs. 4 and 6 indicate that it is unlikely ever to be achieved for any combination of two or more materials of differing acoustic impedance. The axial stress distribution is found to be highly non-uniform in both the linear elastic deformation range of the specimen as well as in the plastic deformation range. This non-uniformity level is much more pronounced 
in multi-layer materials consisting of materials with widely different elastic moduli and (yield) strengths, Fig. 8. The presence of a ceramic layer greatly increases the severity of the stress gradient at the interfaces.

There are two processes contributing to this behavior. The first concerns the acoustic impedance $(Z)$ of each material, defined as the product of density $(\rho)$ and acoustic velocity $(C)$ of that material.

$$
Z=\rho C \text {. }
$$

Acoustic impedance is important in the determination of acoustic transmission and reflection at the boundary of two materials having different acoustic impedances. Stress waves are reflected at boundaries where there are differences in acoustic impedance, $Z$. This is commonly referred to as impedance mismatch. The fraction of the incident-wave intensity in reflected waves can be derived because particle velocity and local particle pressures are required to be continuous across the boundary between materials. Formulation for acoustic reflection $\left(R_{\text {coef }}\right)$ and transmission coefficient $\left(T_{\text {coef }}\right)$ are given below for a wave-entering medium 2 from medium 1:

$$
\begin{aligned}
& R_{\text {coef }}=\left(\frac{Z_{2}-Z_{1}}{Z_{2}+Z_{1}}\right)^{2}, \\
& T_{\text {coef }}=1-R_{\text {coef }} .
\end{aligned}
$$

The transmission and reflection coefficients in the ceramic-copper interface are 0.996 and 0.004 , respectively, while those for the ceramic-aluminum interface are 0.787 and 0.213 , respectively. Data from the incident and transmitter bars show that a significantly greater fraction of the incident wave is reflected straight back to the incident bar in ceramic/aluminum case as compared to ceramic/copper case: this can also be inferred from the shape of the initial stress rise data of Figs. 4(a) and 5(a). For comparison, the transmission and reflection coefficients in the copper/aluminum interface are 0.829 and 0.171 , respectively. Stress values and the magnitude of the stress gradient inside the layers are consequently lower than those of the ceramic/copper case.

The second process contributing to the observed behavior of the present bi-layer samples concerns the relative elastic limits of the components. The SHPB apparatus imposes a displacement on the sample. In the case of a material with a high modulus and elastic limit (e.g., the ceramic) this displacement leads to the generation of a large stress interval, whereas for a material of lower modulus and/or lower elastic limit (e.g., a metal) a significantly lower stress interval is possible.

A further difference also arises in this second case, since a metal with a high strain-hardening exponent will be able to exhibit a wider range of stresses than a metal with a lower strain-hardening exponent. In the present study, the strain-hardening exponent for $\mathrm{Al}$ was determined to be 0.07 , while that for $\mathrm{Cu}$ was 0.14 . Consequently, for equal increments of imposed strain, the $\mathrm{Cu}$ can sustain a significantly greater stress range than the aluminum. The situation is shown schematically in Fig. 13, for a ceramic and two metals of similar yield stress but differing work hardening exponents, all subjected to the same imposed strain of $\Delta \varepsilon$ and the relative stress ranges are seen to be significantly different in each case. Since the present metals differed in their yield stress, elastic modulus, and strain hardening exponents, the present situation is quite complex and further work is underway to separate the relative contributions of these three factors.

The picture that emerges, then, is that wave propagation in multi-layer materials is significantly more complex than in monolithic materials and cannot be treated by simple superposition principles. Impact on multi-layer materials can produce severe stress inhomogeneities at interfaces as well as serious stress gradients within the layers themselves. Brittle layers are shown to be highly susceptible to the formation of steep stress (strain) gradients and are, therefore, very likely to fracture. More ductile materials may be able to accommodate these gradients via plastic deformation. The existence of this type of gradient in composite materials could be expected to lead to delamination and other fracture modes, the locations of which could be predicted from the present modeling approach.

The ability of the metallic component to undergo plastic deformation contributed significantly to reducing the severity of stress concentrations in these samples and can also delay the rate of stress increase in the ceramic layer. By separating the relative contributions of yield stress, strain hardening exponent, modulus, and 


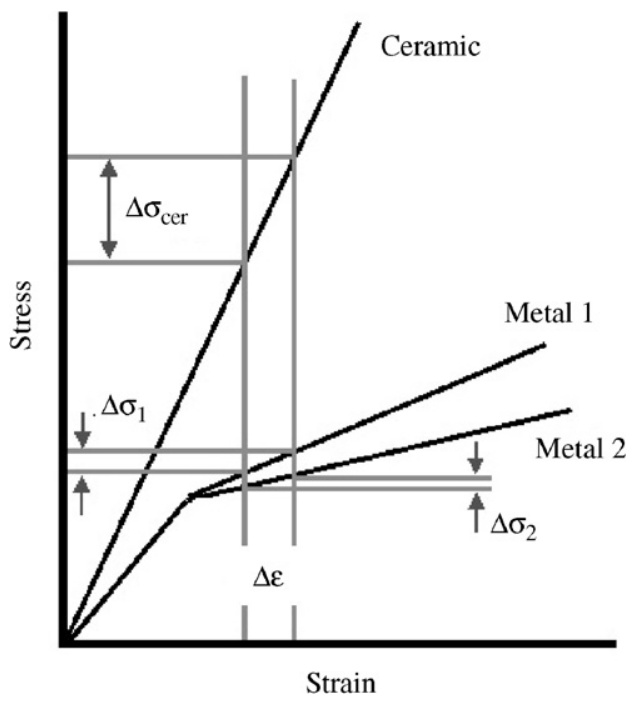

Fig. 13. Schematic diagram showing dependence of stress range on modulus and strain hardening coefficient.

acoustic reflection and transmission coefficients it should be possible to design such bi-material composites to optimize their energy dissipation and fracture characteristics.

\section{Conclusions}

The present work has demonstrated for the first time the feasibility of modeling stress wave propagation in complex multi-layer materials consisting of metals and ceramic with an experimentally validated numerical model. The axial stress distribution was found to be highly non-uniform in the linear elastic deformation range of the specimen, with a tendency to become somewhat more uniform in the plastic deformation range. The degree of non-uniformity is much more pronounced in multi-layer materials consisting of different materials. The presence of a high modulus ceramic layer increases the severity of the stress gradient at the interfaces and it has been shown that the stress may double across the interface. It has been shown that plastic deformation of materials can significantly affect their response to wave propagation and, in particular, that a major effect of plastic deformation is to lead to a more homogeneous stress distribution within the components. Severe stress inhomogeneities may exist in multi-layer materials and these may have serious consequences for the mechanical and other properties. However, plastic deformation has now been shown to limit the maximum attained stress levels within the components, and might provide an avenue to control the location of the fracture initiation sites and damage levels.

\section{Acknowledgments}

The authors gratefully acknowledge financial support from the Army Research Office under Contract Number 47335-EG, Program Manager Dr. Bruce LaMattina, and the National Science Foundation under Grant INT-0242772, Program Manager Dr. O. Shinaishin.

\section{References}

[1] Wilkins ML. Mechanics of penetration and perforation. Int J Eng Sci 1978;16(11):793-807.

[2] Ben-Dor G, Dubinsky A, Elperin T. On the order of plates providing the maximum ballistic limit velocity of a layered armor. Int $\mathbf{J}$ Impact Eng 1999;22(8):741-55.

[3] Ben-Dor G, Dubinsky A, Elperin T. The optimum arrangement of the plates in a multi-layered shield. Int J Solid Struct 2000;37(4):687-96. 
[4] Curran DR, et al. Micromechanical model for comminution and granular flow of brittle material under high-strain rate application to penetration of ceramic targets. Int J Impact Eng 1993;13(1):53-83.

[5] Gailly BA, Espinosa HD. Modelling of failure mode transition in ballistic penetration with a continuum model describing microcracking and flow of pulverized media. Int J Numer Methods Eng 2002;54(3):365-98.

[6] Shockey DA, et al. Failure phenomenology of confined ceramic targets and impacting rods. Int J Impact Eng 1990;9(3):263-75.

[7] Zavattieri PD, Raghuram PV, Espinosa HD. A computational model of ceramic microstructures subjected to multi-axial dynamic loading. J. Mech Phys Solids 2001;49(1):27-68.

[8] Potti SV, Sun CT. Prediction of impact induced penetration and delamination in thick composite laminates. Int J Impact Eng 1997;19(1):31-48.

[9] Abrate S. Impact on laminated composites: recent advances. Appl Mech Rev 1994;47(11):517-44.

[10] Corbett GG, Reid SR, Johnson W. Impact loading of plates and shells by free-flying projectiles: a review. Int J Impact Eng 1996;18(2):141-230.

[11] Myungsoo P, Yoo J, Chung DT. An optimization of a multi-layered plate under ballistic impact. Int J Solid Struct 2005;42(1):123-37.

[12] Woodward RL, Cimpoeru SJ. A study of the perforation of aluminium laminate targets. Int J Impact Eng 1998;21(3):117-31.

[13] Woodward RL, Tracey SR, Crouch IG. The response of homogeneous and laminated metallic sheet material to ballistic impact. J Phys III 1991;1(C3):277-82.

[14] Radin J, Goldsmith W. Normal projectile penetration and perforation of layered targets. Int J Impact Eng 1988;7(2):229-59.

[15] Benloulo ISC, Sanchez-Galvez V. A new analytical model to simulate impact onto ceramic/composite armors. Int J Impact Eng 1998;21(6):461-71.

[16] Hazell PJ, Fellows NA, Hetherington JG. A note on the behind armour effects from perforated alumina/aluminium targets. Int J Impact Eng 1998;21(7):589-95.

[17] Hetherington JG, Rajagopalan BP. An investigation into the energy absorbed during ballistic perforation of composite armors. Int $\mathbf{J}$ Impact Eng 1991;11(1):33-40.

[18] Polo RZ, Sanchez-Galvez V. Using an analytical model of simulation in the design of lightweight armours. Simulation 1998;70(3):175-81.

[19] Zaera R, Sanchez-Galvez V. Analytical modelling of normal and oblique ballistic impact on ceramic/metal lightweight armours. Int J Impact Eng 1998;21(3):133-48.

[20] Chandra N, Chen XL, Rajendran AM. The effect of material heterogeneity on the shock response of layered systems in plate impact tests. J Compos Technol Res 2002;24(4):232-8.

[21] Gama BA, et al. Aluminum foam integral armor: a new dimension in armor design. Compos Struct 2001;52(3-4):381-95.

[22] Li Y, Ramesh KT, Chin ESC. Dynamic characterization of layered and graded structures under impulsive loading. Int J Solid Struct 2001;38(34-35):6045-61.

[23] Tasdemirci A, Hall IW. Experimental and modeling studies of stress wave propagation in multi-layer composite materials: low modulus interlayer effects. J Compos Mater 2005;39(11):981-1005.

[24] Tasdemirci A, et al. Stress wave propagation effects in two- and three-layered composite materials. J Compos Mater 2004;38(12):995-1009.

[25] Liu LS, Zhang QJ. Reflected characteristics of interface between ceramic and ceramic/metal graded materials on elastic wave. J Wuhan Uni. Technol-Mater Sci Ed 2004;19(3) 54-+.

[26] Liu LS, et al. Impact characteristic analysis of ceramic/metal FGM. In: Functionally Graded Materials VII. 2003. p. 641-4.

[27] Liu LS, Zhang QJ, Zhai PC. The optimization design of metal/ceramic FGM armor with neural net and conjugate gradient method. In: Functionally Graded Materials VII, 2003. p. 791-5.

[28] Bruck HA. A one-dimensional model for designing functionally graded materials to manage stress waves. Int $\mathbf{J}$ Solid Struct 2000;37(44):6383-95.

[29] Gooch WAC, Burkins BHC, Palicka MS, Rubin R, Ravichandran JR. Development and ballistic testing of a functionally gradient ceramic/metal applique. Mater Sci Forum 1999;308-311:614-21.

[30] Riou P, Denoual C, Cottenot CE. Visualization of the damage evolution in impacted silicon carbide ceramics. Int J Impact Eng 1998;21(4):225-35.

[31] Strassburger E, et al. An experimental approach to validate damage evolution laws for brittle materials. J Phys IV 1997;7(C3):909-14.

[32] Riou P, et al. Impact damage on silicon-carbide - first results. J Phys IV 1994;4(C8):281-7.

[33] Forquin $\mathrm{P}$, et al. Effect of aluminum reinforcement on the dynamic fragmentation of SiC ceramics. Int $\mathrm{J}$ Impact Eng 2003;28(10):1061-76.

[34] House JW, Gillis PP. Strain rate effects on texture evolution in OFE copper. In: Textures Of Materials, Pts 1 And 2. 2002. p. 547-51.

[35] Masuda T, et al. Effects of strain rate on deformation behavior of A6061-T6 aluminum alloy. In: Thermec'2003, Pts 1-5. 2003, p. 285-290.

[36] Stevenson ME, Jones SE, Bradt RC. The high strain rate dynamic stress-strain curve for OFHC copper. Mater Sci Res Int 2003;9(3):187-95.

[37] Zhu YZ, et al. Constitutive equation of annealed copper with high conductivity for deformation at high strain rates. Trans Nonferrous Metals Soc China 2004;14(4):775-8.

[38] Guden M, Hall IW. Dynamic properties of metal matrix composites: a comparative study. Mater Sci Eng A-Struct Mater Propert Microstruct Process 1998;242(1-2):141-52. 